\title{
Comments on Lowenstein et al.: Incidence and lifetime risk of pelvic organ prolapse surgery in Denmark from 1977 to 2009
}

\author{
Hans Peter Dietz ${ }^{1}$
}

Received: 23 February 2015 / Accepted: 7 May 2015 /Published online: 19 May 2015

(C) The International Urogynecological Association 2015

Dear Sir,

Please let me comment on the paper by Løwenstein et al. [1], which I found very interesting. It describes a substantial reduction in the lifetime risk for prolapse surgery in Denmark between the late 1970 s and 2008 , from 26.9 to $18.7 \%$., i.e. of about $30 \%$. I was very impressed with this work and can add two pieces of information others may find helpful.

The first relates to the latency between the primary risk factor for the development of pelvic organ prolapse (POP), i.e. the first vaginal delivery, and presentation for prolapse surgery. We have recently shown that this latency is over 30 years [2]. Hence, any changes in obstetric practice would be expected to take about a generation to fully impact on POP surgery prevalence.

The second involves the main risk factor for the development of POP, forceps delivery. We do know that forceps is strongly associated with avulsion, which in turn is the primary risk factor for anterior and central compartment prolapse. The odds ratio for avulsion in forceps relative to vacuum in 9 studies to date, involving about 3,000 women from 6 countries, is estimated to be between 3.4 and 11.4 [3]. In the 1960s, vacuum began to replace forceps for vaginal operative delivery, and to my knowledge forceps is now virtually unknown in Denmark.

Given our own data on avulsion after vacuum and forceps in now over 850 low-risk primiparae at term [4], we would expect a reduction in avulsion rates by about one third if forceps was completely replaced by vacuum. Resulting from that, one would predict a substantial reduction in prolapse surgery in Denmark from the 1970s onwards, and this is clearly what Løwenstein et al. have shown.

While there may be multiple other factors, including demographic changes, changed patient and doctor preferences and changes in technology, that may affect the lifetime risk of POP surgery, any alterations in primary risk factors should be considered, especially if they provide a potential explanation for such substantial shifts in service delivery.

Funding Nil.

Conflicts of interest H.P. Dietz has received unrestricted educational grants from GE Medical.

\section{References}

1. Løwenstein E, Ottesen B, Gimbel H (2015) Incidence and lifetime risk of pelvic organ prolapse surgery in Denmark from 1977 to 2009. Int Urogynecol J 26(1):49-55

2. Thomas V, Shek KL, Guzmán Rojas R et al (2015) Temporal latency between pelvic floor trauma and presentation for prolapse surgery: a retrospective observational study. Int Urogynecol J, accepted for publication

3. Dietz HP (2015) Forceps: towards obsolescence or revival? Acta Obstet Gynecol Scand 94(4):347-351. doi:10.1111/aogs.12592

4. Caudwell-Hall J, Atan IK, Martin A et al (2014) Intrapartum predictors of pelvic floor trauma. Ultrasound Obstet Gynecol 44(S1):21-22

Hans Peter Dietz

hpdietz@bigpond.com

1 Obstetrics and Gynaecology, Sydney Medical School Nepean, Nepean Hospital, Penrith, NSW 2750, Australia 